\title{
Students' Online Interaction Styles: Can They Change?
}

\author{
Dazhi Yang \\ Jennifer C. Richardson \\ Purdue University
}

\begin{abstract}
Past studies indicate that students demonstrate different online interaction styles, which consist of the ways or habits students acquire knowledge from computer-mediated discussions (Sutton, 2001). Such interaction styles include the active interaction style (Beaudion, 2002), the vicarious interaction style (Sutton, 2001), and the mixed or balanced-interaction style. The purpose of this exploratory study was to further investigate whether students' online interaction styles changed during a course utilizing asynchronous computer-mediated discussions; and if so how and why they changed. Results indicate that such changes did take place as $44 \%$ of participants adjusted to more active learning styles as the courses progressed. This study has implications for the design of online learning environments, instructor's role in online courses, and educational tools to facilitate students in adapting to more active interaction styles in computer-mediated learning environments.
\end{abstract}

Keywords: online interaction styles, learning styles, learning preferences

\section{Introduction}

Online and distance learning has exploded exponentially around the globe. In North America, there are fully online universities (e.g. the University of Phoenix and Capella University) and degrees offered completely online at Athabasca University and the Canadian Virtual University. Similarly, in Asia, there are the Open University of Malaysia and India's Indira Gandhi National Open University. Online learning has also invaded K-12 education. In 2007, there was an estimated of 1 million K-12 online course enrollment in America (NACOL, 2007). Currently, the number of online courses continues to grow. Although the emergence of Web 2.0 technologies such as MySpace and Blogger greatly facilitates this wave of online and distance learning, new questions about pedagogical value and methods of effectively integrating them have also emerged (Thiessen, 2001). In addition, due to access and type of security issues involved (Evers, 2006), online instructors have yet to find a way to fully adopt these technologies. Therefore, it is not surprising that asynchronous online discussions, which are usually mediated or assisted by computers, is still a common pedagogical practice in online courses (McLoughlin \& Luca, 2000). Research shows that when asynchronous computer-mediated discussions are appropriately implemented they can increase knowledge and understanding of course materials (Garrison, Anderson, \& Archer, 2001). 
In asynchronous computer-mediated discussions, students can discuss and reflect on course materials and post their ideas and thoughts within a course management system or tool, such as Moodle or Blackboard. Students are also usually required to respond to their peers' postings. During such discussions, students display different online interaction styles, which are defined as the ways or habits students acquire knowledge from the discussions (Sutton, 2001). For instance, some students are constantly participating or posting more than the course requires, which allows them to be categorized, as Sutton defines, as active interaction style learners (Beaudion, 2002). Some are actively observing and processing both sides of the interaction from others (peers and the instructor) without direct participation in the discussions and are known as vicarious interaction style learners (Sutton, 2001). Furthermore, according to our online teaching and discussion facilitation experiences, another group of learners also exists, who may neither be actively involved nor a complete observer, whom we refer to as the mixed or balanced-interaction style learners. For students categorized within the mixed or balanced-interaction style, their levels of effort in computer-mediated discussions are approximately equal to the minimum amount of postings required by a course.

Different online participation styles and behaviors, especially active online participation, have different impact on student learning and learning experience (Moore, 1989; Sutton, 2000; Swan, 2002). Thus, this exploratory study was intended to find out whether students' online interaction styles could change during the course of online discussions, for example, from the vicarious interaction style to the active interaction style or vice versa.

\section{Literature Review}

\subsection{Online Interaction Styles}

Because of different online interaction styles, students utilize different learning processes or manners of learning in computermediated discussions. The "manner in which information is learned" affects learning transfer, which is the ability to apply learning to new situations (Bransford \& Schwartz, 1999, p. 64). Thus, students' online interaction styles in asynchronous computer-mediated discussions not only reflect students' participation behaviors, but can also affect students' learning and learning transfer.

The active interaction style involves students continuously participating and responding to discussion questions and their peers' postings, generally more than they are required to. The constant participation and responses may reflect students' active encoding and decoding of course materials and others' ideas. In fact, educational researchers argue that active student participation and interaction is critical to the success of online learning (Moallem, 2003; Spitzer, 2001; Zirkin \& Sumler, 1995). In a socially constructed knowledge learning environment, such as asynchronous computer-mediated discussions, students need to be actively participating to construct their own learning (Dewey, 1884).

Vicarious interaction style, which involves actively observing and processing both sides of the interaction and discussions among other participants, benefits from vicarious learning characteristics (Sutton, 2000) such as learning from observing others (Bandura, 1986) and reading postings (Lee, Dineen, McKendree, \& Mayes, 1999). Vicarious learning has two phases: the acquisition phase and the performance phase (Masia \& Chase, 1997). Masia and Chase (1997), in their description of 
the phases, further point out that there is often a gap in terms of time between the two phases. The completion of the acquisition phase is a cognitive representation of the acquired knowledge and skills. It is also a subsequent display of student's learning. The performance phase occurs when learners apply the acquired knowledge and skills into new situations. Thus, vicarious learning occurs as a result of observation, active process of ideas and information, and personal reflection (Masia $\&$ Chase, 1997). Students who have vicarious interaction styles appear to be observers in asynchronous computer-mediated discussions. Although vicarious learners can benefit from online discussions, the benefits of vicarious interaction "will not be as great as in the case of direct [interaction]" (Sutton, 2000, p.23). Recently, educational researchers concluded that students should be actively creating rather than consuming knowledge (Collis \& Moonen, 2001; Grabinger \& Dunlap, 2002). Furthermore, if there is no visible participation (e.g., postings), how can we know whether the acquisition phase of knowledge and skills or the performance phase has been reached by learners?

The mixed or balanced-interaction style refers to learners who are neither actively nor passively involved. The mixed style learners may be engaged in active encoding and decoding at one point while observing the interactions at another point during the learning process. Students categorized into mixed or balanced-interaction style usually do what they have to do to meet course requirements rather than being completely immersed in discussions. As Anderson (2008) argues, students need to be actively involved in a learning process because active interaction is a result of aggregated contribution of all participants. Moreover, for the purpose of online learning community building and a better leaning experience, it is also highly desirable that all participants are completely immersed in discussions.

Given this, designers and instructors of computer-mediated discussions and online courses should be aware of students' different interaction styles and try to promote more active and direct interaction. However, this is not without challenges. To address these challenges, we first need to investigate whether students can change or adapt to more active interaction styles during the course of computermediated discussions.

\subsection{Online Learning Styles/Preferences}

In order to investigate whether students can change or adapt to more active online interaction styles, we reviewed past studies on students' online interaction styles in computer-mediated discussions. In particular, we reviewed studies that examined the factors impacting online students' participation and interaction in asynchronous computermediated and text discussions. Past studies report that individual learning styles are among the main factors that affect students' direct participation in computer-mediated discussions (Beaudion, 2002; Kovacic, 2004). Individual learning styles include the cognitive, affective, and psychological traits that students reveal when interacting with, perceiving, and responding to others (Keefe, 1979). Individual learning styles play a major role in the way students learn and process information in computer-mediated learning environments (Assis, Danchak, \& Polhemus, 2006; Ford \& Chen, 2000; Riding \& Cheema, 1991). This finding and Keefe's definition of learning styles lead us to believe that individual learning styles are static characteristics (Assis, Danchak, \& Polhemus, 2006; Pena, Marzo, \& Rosa; 2002), which are fixed and do not change during a learning process. In addition, because individual learning styles affect and 
determine individual learning preferences (Louange, 2007), most people believe that individual learning preferences are also static and fixed.

In view of past research that indicates learning styles and preferences are static, some researchers and practitioners suggest a focus on online course design and instruction that would meet diverse learning styles (Fresen, 2005; Janicki \& Liegle, 2001; Johnson \& Arogan, 2003). However, in order to accommodate learning styles and preferences, online instructors are often puzzled with how to meet diverse student needs when facing twenty, thirty, or hundreds of students. Despite the claim that "online environments can be particularly well suited to some learning styles" (Illinois Online Network, 2008, 『1), researchers have found most students display a dual learning style in online courses and there is no one single dominant learning preference (Butler \& Pinto-Zipp, 2006). Similarly, Fahy and Ally (2005) report that students' cognitive styles are not significantly correlated with their preference for instructional delivery modes such as traditional face-to-face, online, or blended learning. Therefore, we can presume both students' online interaction styles and individual learning preferences can change during the course of certain computer-mediated discussions due to their dynamic characteristics. Consequently, online instructors are able to help students adapt to more active online interactions or learning styles and help students benefit from direct interaction. This hypothesis is in line with Kolb's work (1984), which states that individual learning styles are dynamic and change over time due to elements such as learning objectives and learners' role in the learning process. As such, we were interested in exploring the changes of students' online interaction styles in computer-mediated discussions. Specifically we focused on:
- What kinds of interaction styles (active, vicarious, or mixed/balancedinteraction styles) did students display in asynchronous computer-mediated discussions?

- Did students' interaction styles change during a semester-long course utilizing asynchronous computer-mediated discussions? And if so,

- Why and how did the students change their interaction styles during a semesterlong course utilizing asynchronous computer-mediated discussions?

\section{Method}

\subsection{Context and Participants}

Two graduate Educational Technology courses at a large Midwestern university were chosen for this study. The first course was a foundations of distance education course $(\mathrm{N}=13)$ and the second one was an instructional and learning theories course $(\mathrm{N}=15)$. Both courses were credit-bearing. Asynchronous computer-mediated discussions were the main instructional strategy employed by both courses. All enrolled students were required to participate and post weekly in online forums. They were required to post two to three postings during a one week period with one initial response for the assigned discussion topic(s) and one or two postings to their peers' postings. Students' weekly postings were also graded and accounted for $35 \%$ of their final grades in the distance education course and $30 \%$ in the learning theories course. In both courses, the online discussions lasted for 16 weeks and the instructors actively monitored and facilitated the weekly discussions, which helped both the students and researchers identify students' online interaction styles and further verify whether they changed their online interaction styles. 
Because of the subject matter being studied, both courses attracted students from different fields and schools including education, science, technology, and engineering. In addition, both courses were delivered using WebCT Vista with an initial face-to-face meeting. Thus, the courses further attracted some students who worked full-time or lived far away from the university campus. All students' background information was obtained from the class bios posted in WebCT Vista. Both courses had students with a range of ethnicities (Caucasian, Africa American, Hispanic, and Asian). Students' ages ranged from 21 to more than 40 years of age. Students had different levels of experiences with asynchronous computermediated discussions and online courses. All enrolled students in these two online classes were invited to participate in the study, with $89 \%$ choosing to do so $(25 / 28$ potential participants)

\subsection{Data Collection}

A mixed model research approach was utilized (Johnson \& Christensen, 2004) that allowed for triangulation of data. Quantitative data were collected from an online survey given at the end of the class. The learning objectives, learning environments, course requirements, students' role, etc. in our study were unique, and therefore, an online survey was created. The online survey included Likert-scale items focused on students' online interaction styles, individual learning preferences, and online learning activities. Individual learning preferences in this study refer to one's preference to participating in discussion, reading other postings, and observing the interaction between others in an online environment. The Likert-scale items were created based on definitions of vicarious learning (Bandura, 1986) and vicarious interaction (Sutton, 2000). In addition, several questions came from the work of Dr. Michael
Beaudoin (2002) and were intended to track students "lurking" in the online discussions.

Sample survey questions included: (a) I often processed ideas from reading others' postings even when I was not visibly participating in the online discussion; (b) I was more of an autonomous learner and seldom got too engaged in group online discussion; (c) I preferred interacting and discussing the course materials with others in order to learn more effectively; (d) I would not have participated in the online discussions/postings if it was not graded; and (e) I preferred reading others' postings and comments to writing my own discussion postings. In addition, in order to verify students' self-identification of their online interaction styles, quantitative records of students' login activities such as frequencies of logins and time durations of each login in WebCT Vista of each student were obtained and examined.

Qualitative data were collected from openended questions embedded in the online survey. The open-ended questions asked for students' experiences and feedback on the asynchronous computer-mediated discussions. Participants were also asked if their online interaction styles had changed as the courses proceeded and why their online interaction styles changed if there was such a change. The online survey was pilot-tested in an online graduate educational technology course and modified accordingly to increase the face and content validity before it was administered to the study participants. Twenty-five students voluntarily responded to the survey (12 students from the first course; 13 from the second one). Furthermore, followup questions seeking clarification, including soliciting explanations of influential factors causing such change, were sent via email to those participants who indicated they had changed their online interaction styles as their course proceeded. 


\subsection{Data Analysis}

All survey data including those from the Likert-type questions, the open-ended questions, data from students' login activities, and follow up emails were analyzed. During the data analysis process, the researchers grouped similar survey questions together in order to check the consistency of students' responses. Confirmation questions, which mean two questions were essentially the same but with different wordings, were placed in different places throughout the survey to ensure appropriate identifications and classifications of different interaction styles and learning preferences. In addition, the results of the survey data indicating students' online interaction styles and learning preferences were triangulated with frequencies of their logins, number of postings they read, and number of postings they posted in the online forums. The qualitative responses from the open-ended questions were also analyzed. This analysis was focused on students' experiences and feedback on the asynchronous computermediated discussions and why some students changed their online interaction styles.

\section{Results}

Results of the survey data triangulated with students' login activities indicated that students $(\mathrm{n}=25)$ displayed various online interaction styles (Table 1) in asynchronous computer-mediated discussions. As expected, more than half of the students displayed active interaction styles due to instructor's constant presence and facilitation in the discussions (Berge, 1995). However, seven students displayed vicarious interaction styles and five students demonstrated mixed or balanced-interaction style. The results also showed students had different individual learning preferences (Table 2) in asynchronous computer-mediated discussions.
Table 1. Student Online Interaction Styles

Interaction Style Class 1 Class 2 Total (Subtotal/

Percent)

\begin{tabular}{llll}
\hline $\begin{array}{l}\text { Active } \\
\text { interaction }\end{array}$ & 6 & 7 & $13 / 52 \%$ \\
$\begin{array}{l}\text { Vicarious } \\
\text { interaction }\end{array}$ & 3 & 4 & $7 / 28 \%$ \\
$\begin{array}{l}\text { Mixed } \\
\text { interaction }\end{array}$ & 3 & 2 & $5 / 20 \%$ \\
\hline
\end{tabular}

Table 2. Student Online Learning Preferences

\begin{tabular}{lcc}
\hline Learning & Class 1 Class 2 & Total \\
Preferences & (Subtotal/ \\
Percent)
\end{tabular}

\begin{tabular}{llll}
\hline $\begin{array}{l}\text { Preferred to } \\
\text { discuss content } \\
\text { materials with } \\
\text { others }\end{array}$ & 7 & 8 & $15 / 60 \%$ \\
$\begin{array}{l}\text { Processed ideas } \\
\text { from reading } \\
\text { others' postings } \\
\text { without visible } \\
\text { participation }\end{array}$ & 11 & 9 & $20 / 80 \%$ \\
$\begin{array}{l}\text { Was an } \\
\text { autonomous } \\
\text { learner and } \\
\text { seldom got too } \\
\text { engaged in group } \\
\text { online discussion }\end{array}$ & & & \\
$\begin{array}{l}\text { Preferred to read } \\
\text { others' postings }\end{array}$ & 6 & 7 & \\
\hline
\end{tabular}


The survey data indicated that more than half of the students $(n=13)$ did change their interaction styles during the course of the asynchronous computer-mediated discussions (Table 3). Most of those who changed $(n=11)$ their interaction styles became more actively involved in the discussions $(n=11)$, which was confirmed by an increased number of posts, and students' login activities. However, two participants did not follow this pattern according to the results of Likert survey and open-ended questions. One student appeared to have actively participated in the discussions initially and then changed to a mixed-interaction style because she felt her "discussion[s] were not encouraged" and only a few participants replied to or commented on her postings. The second participant indicated she switched to a more vicarious style after she realized she "was completely new to the field of education"; the course on foundations of distance education was her first education course.

Table 3. The Change of Online Interaction Styles

\begin{tabular}{lccc}
\hline $\begin{array}{l}\text { Interaction } \\
\text { Style }\end{array}$ & Class 1 & Class 2 & $\begin{array}{c}\text { Total } \\
\text { (Subtotal/ } \\
\text { Percent) }\end{array}$ \\
\hline Changed & 5 & 8 & $13 / 52 \%$ \\
$\begin{array}{l}\text { Has not } \\
\text { changed }\end{array}$ & 4 & 5 & $9 / 36 \%$ \\
\begin{tabular}{l} 
Not sure \\
\hline
\end{tabular} & 3 & 0 & $3 / 12 \%$ \\
\hline
\end{tabular}

Based on the survey results, one of the main factors impacting students' online interaction styles was individual learning preferences, such as preference for discussing course materials with others $(n=15)$ and preference for reading others' postings $(n=13)$. We found that the number of participants $(\mathrm{n}=13)$ who displayed active interaction styles was close to the number of participants $(n=15)$ who preferred to discuss course materials with others. However, we also found that there was no strong indication of specific learning preferences (e.g., preferred to discuss content materials with others) for specific online interaction styles (e.g., active, vicarious, or mixed), which means that although different students displayed different learning preferences they could have had the same interaction style. In addition, from student responses to the open-ended questions, factors such as the instructor's presence and involvement in asynchronous computer-mediated discussions and course requirements (e.g., requiring peer feedback) also impacted students' participation and online interaction styles. In fact, more than $50 \%$ of the students indicated in the survey that the instructor's presence and involvement in discussions and the course requirements were critical in shaping and changing their participation and posting habit in online discussions. Furthermore, the difficulty level of the content, the student's familiarity with the subject, the availability of time, and the class size also impacted students' online interaction. Finally, from the survey results, most participants $(n=20)$ indicated they "processed ideas from reading others' postings without visible participation," which verified that most participants were involved in vicarious interaction and benefited from vicarious learning.

According to the data from open-ended questions, students who have changed their interaction styles provided different explanations for such change. Different instructional strategies such as group discussions, role playing, and debates, helped students change their styles of postings and interactions in the computer-mediated environment. As one participant responded: 
...team work, week leaders, ... different activities (i.e. case study writing [that was] not only [general] discussion), weekly summarizing from [the] instructor, [and] more feedback from other teams [motivated me and prompted me to achieve a deeper understanding of the course materials and the others' postings].

Knowing the content and course requirements, such as being familiar with the subject and knowing participation requirements and guidelines, also affected participants' online interaction styles. As one participant stated:

... I was unsure of how online postings work[ed] the first few weeks of the semester and became a more active participant after I understood the online course requirements better...

Anotherparticipanthada similarexplanation of his or her change of online interaction style:

Initially I wasn't sure how to post in a way that would contribute and leave it open for others -- and initially my comments were pretty superficial, I had to reach to get more depth....

Other factors such as being open-minded and receiving insightful feedback from both peers and the instructor also helped some participants become more actively involved in the discussions. Despite some students not actively involved in the discussions due to different factors, most students responded they had a great learning experience and learned a lot in the discussions and the course.

\section{Discussion}

This study demonstrated that students do utilize various interaction styles (active interaction, vicarious interaction, and mixed or balanced-interaction style) in computermediated discussions. The study also shows students' online interaction styles are dynamic rather than static in an online course, as demonstrated by the change to more active learning styles as the courses progressed by $44 \%$ of participants. It is unlikely that every student will be actively participating in online discussions at all times; however, students can still have an effective learning experience if most students are actively involved in the discussion or a learning process most of the time. For vicarious learners, because they prefer to observe, using traditional assessment of online discussions such as simply counting the number of postings may be a disadvantage for them. Chances are that online instructors will have vicarious learners in her or his online discussions. Thus, when making assessment decisions for computer-mediated discussions, online instructors should be aware of this factor. Instructors may need to focus on learning transfer in order to fairly assess those vicarious interaction style students. For example, applying what students were supposed to learn in a new situation should be emphasized in the assessment.

We have heard too much about accommodating individual learning styles and preferences. This deeply rooted belief has led to a one-way street of educational practice with puzzled and frustrated instructors and learners being easy to give up. In this study, we found that although individual learning preferences were a strong factor impacting students' online interaction styles, there was no direct association between the two. Even more interesting was that we found that students did change their interaction styles during the course of computer-mediated discussions. Maybe now is the time to shift the effort of accommodating individual differences to facilitate students in adapting to learn in different modalities. 
For example, online instructors can adopt instructional strategies within online discussions that encourage students to become more active, such as small group discussions, role playing, and debates. Specifically, when designing online learning environments and online tools, designers and instructors should focus on strategies that can help online students actively interact with others and effectively learn and communicate in diverse modalities. For example, the emergence of the Web $2.0 \mathrm{can}$ help students acquire different learning skills to communicate and construct knowledge such as writing (in a blog), listening (to a Podcast), verbally presenting (via Skype), and observing (a live scene online).

The study also showed that instructor's presence and involvement in asynchronous computer-mediated discussions was one of the main factors affecting students' online interaction styles. Thus, online instructors are able to influence and help students change their predominant interaction styles in computermediated learning environments. Such finding provides a new direction of focus in encouraging and helping students use and develop multiple learning modalities in the design of computermediated learning environments and tools.

\section{Conclusion}

This study has implications not only for effective design and organization of computermediated discussions, but also for online and blended learning environments. The results provide a new direction for designing effective online tools and instruction to facilitate students in adapting to more active interaction styles in computer-mediated learning environments. However, because this was an exploratory study with a small sample size, we need more data to fully understand why and how students' online instruction styles change. In addition, we need to better understand how to help students, especially those vicarious and mixed or balanced-interaction style students, achieve a more satisfactory learning experience. Similar studies will further shed light on strategies that can be utilized in the design of emerging educational technologies and tools for online and distance education. Finally, as online courses afford more situations (e.g., watching an interactive video) where learners can gain knowledge by observing others instead of active participation (Craig, Driscoll, \& Gholson, 2004), differing interaction styles, in particular the vicarious interaction style, should be taken into account for the purpose of assessment.

\section{References}

Anderson, T. (2008). Towards a theory of online learning. In T. Anderson's The Theory And Practice Of Online Learning ( $2^{\text {nd }}$ ed) (pp.45-74). AU: Athabasca University.

Assis, A., Danchak, M., \& Polhemus, L. (2006). Optimizing instruction using adaptive hypermedia. In Kinshuk et al., (Eds.) Proceedings of the $6^{\text {th }}$ IEEE International Conference on Advanced Learning Technologies IEEE Computer Society (pp. 779-783).

Bandura, A. (1986). Social foundations of thought and action: A social cognitive theory. Englewood Cliffs, NJ: PrenticeHall.

Bransford, J. D., \& Schwartz, D. L. (1999). Rethinking transfer: A simple proposal with multiple implications. Review of Research in Education, 24, 61-100.

Beaudoin, M. F. (2002). Learning or lurking? Tracking the "invisible" online student. The Internet and Higher Education, 5, 147-155.

Berge,Z.(1995). Therole of the online instructor/ facilitator. Educational Technology, 35(1), 22-30.

Butler, T. J., \& Pinto-Zipp, G. (2006). Students' learning styles and their preferences for 
online instructional methods. Journal of Educational Technology Systems, 34(2), 199-221.

Collis, B., \& Moonen, J. (2001). Flexible Learning in a Digital World: Experiences and Expectations. London: Koogan Page.

Craig, S. D., Driscoll, D. M., \& Gholson, B. (2004). Constructing knowledge from dialog in an intelligent tutoring system: Interactive learning, vicarious learning, and pedagogical agents. Journal of Educational Multimedia and Hypermedia, 13(2), 163183.

Dewey, J. (1884, January). The new psychology. Andover Review, 2, 278-189. Retrieved May 30, 2008, from http://psychclassics. yorku.ca/Dewey/newpsych.htm

Evers, J. (2006). The security risk in Web 2.0. Retrieved June 28, 2008, from http:// news.cnet.com/The-security-risk-in-Web2.0/2100-1002_3-6099228.html

Fahy, P. J., \& Ally, M. (2005). Student learning style and asynchronous computer-mediated conferencing (CMC) interaction. The American Journal of Distance Education, 19(1), 5-22. Retrieved December 12, 2006, from http:// www.leaonline.com/doi/pdf/10.1207/ s15389286ajde1901_2?cookieSet $=1$

Ford, N., \& Chen, S. (2000) Individual differences, hypermedia navigation and learning: an empirical study. Journal of Educational Multimedia and Hypermedia, 9, 281-312.

Fresen, J. W. (2005). Quality assurance practice in online (web-supported) learning in higher education: An exploratory study. Retrieved on May, 16, 2005, from http://upetd.up.ac. za/thesis/available/etd-02172005-134301/ unrestricted/04chapter4.pdf

Garrison, D. R., Anderson, T., \& Archer, W. (2001). Critical thinking, cognitive presence, and computer conferencing in distance education. The American Journal of Distance Education, 15(1), 7-23.
Grabinger, S., \& Dunlap, J. (2002). Applying the REAL model to web-based instruction: An overview. In P. Barker \& S. Rebelsky (Eds.), Proceedings of World Conference on Educational Multimedia, Hypermedia and Telecommunications 2002 (pp. 447452). Chesapeake, VA: AACE.

Illinois Online Network. (2008). Learning styles and the online environment. Retrieved April 6, 2008, from http://www. ion.uillinois.edu/resources/tutorials/id/ learningStyles.asp

Janicki, T., \& Liegle, J. O. (2001). Development and evaluation of a framework for creating web-based learning modules: a pedagogical and systems approach. Journal of Asynchronous Learning Networks, 5(1), 58-84.

Johnson, B., \& Christensen, L. (2004). Educational research: Quantitative, qualitative, and mixed approaches (2nd ed.). Boston, MA: Pearson Education Inc.

Johnson, S. D., \& Arogan, S. R. (2003). An instructional strategy framework for online learning environments. New Directions for Adult and Continuing Education, 100, 3143.

Keefe, J. W. (1979). Learning style: An overview. In NASSP's Student learning styles: Diagnosing and prescribing programs (pp.1-17). Reston, VA: National Association of Secondary School Principals.

Kolb, D. A. (1984). Experiential learning: Experience as the source of learning and development. Englewood Cliffs, N.J: Prentice-Hall.

Kovacic, Z. J. (2004). Learning styles, sociodemographics and level of participation in a discussion forum. Retrieved July 1, 2008, from http://ausweb. scu.edu.au/aw04/papers/refereed/kovacic/ paper.html

Lee, J., Dineen, F., McKendree, J., \& Mayes, T. (1999, April). Vicarious learning: Cognitive 
and linguistic effects of observing peer discussion. Paper presented at the annual meeting of the American Educational Research Association, Montreal, Canada.

Louange, J. E. G. (2007). An examination of the relationships between teaching and learning styles, and the number sense and problem solving ability of Year 7 students. RetrievedMarch 11,2008, from http://www. eric.ed.gov/ERICDocs/data/ericdocs2sq1/ content_storage_01/0000019b/80/3d/43/ db.pdf

Masia, C. C., \& Chase, P. N. (1997). Vicarious learning revisited: A contemporary behavior analytic interpretation. Journal of Behavior Therapy and Experimental Psychiatry, 28, 41-51.

McLaughlin, C., \& Luca, J. (2000). Cognitive engagement and higher order thinking through computer conferencing: We know why but do we know how? Retrieved November 11, 2006, from Teaching and Learning Forum 2000 http://www.lsn. curtin.edu.au/tlf/tlf2000/mcloughlin.html.

Moallem, M. (2003). An interactive online course: A collaborative design model. Educational Technology Research and Development, 51(4), 85-103.

Moore, M.G. (1989). Three types of interaction.

The American Journal of Distance Education, 3(2), 1-6. Retrieved January 24, 2005, from http:/www.ajde.com/Contents/ vol3_2.htm\#editorial

North American Council for Online Learning (NACOL). (2007). Online learning facts. Retrieved June 20, 2008, from http://www. nacol.org/media/

Riding, R., \& Cheema, I. (1991). Cognitive styles -- an overview and integration. Educational Psychology, 11(3-4), 193215.

Pena, C-I., Marzo, J-L., \& Rosa, J.-L.d.1.. (2002). Intelligent agents in a teaching and learning environment on the Web. Proceedings of the 2nd IEEE International
Conference on Advanced Learning Technologies, ICALT2002. Retrieved January 3, 2007, from http://lttf.ieee.org/ icalt2002/proceedings/t104_icalt094_End. pdf

Spitzer, D. R. (2001). Don't forget the hightouch with the high-tech in distance learning. Educational Technology, 61(2), 51-55.

Sutton, L. A. (2000, April). Vicarious interaction: Alearning theory for computermediated communications. Paper presented at the Annual Meeting of the American Educational Research Association. New Orleans, LA.

Sutton, L. A. (2001). The principle of vicarious interaction in computer-mediated communications. International Journal of Educational Telecommunications, 7(3), 223-242.

Swan, K. (2002). Building learning communities in online courses: The importance of interaction. Education, Communication, and Information, 2, 2349. Retrieved September 11, 2008, from http://www.kent.edu/rcet/Publications/ upload/SocPres\%20ECI.pdf

Thiessen, J. (2001). Faculty attitudes in delivering undergraduate distance education. Retrieved May 11, 2007, from http://hdl. handle.net/2194/564

Zirkin, B., \& Sumler, D. (1995). Interactive or non-interactive? That is the question! An annotated bibliography. Journal of Distance Education, 10(1), 95-112. 


\section{Contact the Authors}

Dazhi Yang, Ph.D.

Purdue University

Email: dyang@purdue.edu

Jennifer C. Richardson, Ph.D.

Purdue University

Email: jennrich@purdue.edu 